José Roberto Colombo Júnior

\title{
Efeitos do laser KTP na dissecção laparoscópica do feixe neuro-vascular cavernoso em modelo experimental canino
}

Tese apresentada à Faculdade de Medicina da Universidade de São Paulo para obtenção do título de Doutor em Ciências

Área de Concentração: Urologia

Orientador: Dr. Marcos Francisco Dall'Oglio

São Paulo 
José Roberto Colombo Júnior

\section{Efeitos do laser KTP na dissecção laparoscópica do feixe neuro-vascular cavernoso em modelo experimental canino}

Tese apresentada à Faculdade de Medicina da Universidade de São Paulo para obtenção do título de Doutor em Ciências

Área de Concentração: Urologia

Orientador: Dr. Marcos Francisco Dall'Oglio

São Paulo 


\section{Dedicatória}


Aos meus amados pais, Regina e José Roberto, pelo amor, dedicação, coragem e apoio ilimitados.

Aos meus irmãos, Ricardo e Paula, pelo carinho e apoio sempre presentes.

À minha esposa, Cristiane, pelo estímulo, companheirismo, compreensão e suporte incondicional em minha vida. 
Agradecimentos 


\section{AGRADECIMENTOS}

- Ao meu pai, Dr. José Roberto Colombo, pela minha formação ética e moral, a quem amo, admiro, e é meu exemplo de caráter, dedicação e superação.

- Ao meu irmão, Ricardo, pelo companheirismo, cumplicidade e presença integral em minha vida.

- Ao Dr. Marcos Dall'Oglio, amigo e orientador, pela inestimável colaboração e apoio irrestrito.

- Ao Dr. Marcello Cocuzza, pelo companheirismo, entusiasmo e estímulo constantes, a quem me reservo a honra de poder chamá-lo de irmão.

- Ao Dr. Inderbir Gill, pela amizade e orientação durante meu fellowship no Departamento de Urologia da Cleveland Clinic, e apoio constante durante a elaboração desta tese.

- Aos meus colegas e amigos que fizeram este trabalho possível: GeorgesPascal Haber, Troy Gianduzzo, Monish Aron, Jihad Kaouk e Mihir Desai.

- Ao Prof. Dr. Anuar Mitre, pela amizade, estímulo e valiosa orientação.

- Ao Prof. Dr. Lísias Nogueira Castilho, pela amizade e estímulo constante em busca de novos conhecimentos.

- Ao Dr. Gustavo Caserta Lemos, pela confiança, apoio e orientação.

- A Família Cocuzza, pela amizade e apoio sempre presentes. 
- Ao Prof. Dr. Miguel Srougi, pela orientação e exemplo, e por ter permitido a realização deste trabalho.

- Ao Prof. Dr. Francisco Dénes e Prof. Dr. Nélson Gattás, pelas valiosas sugestões durante a aula de qualificação.

- A Sra. Elisa de Arruda Cruz da Silva, pela ajuda integral durante a pósgraduação.

- A Sra. Maria Hernandez, pela amizade e auxílio durante meu fellowship.

- A todos os Professores, Residentes, Enfermeiros e Funcionários da Disciplina de Urologia do Hospital das Clínicas da Universidade de São Paulo, pela minha formação. 


\section{CONFLITO DE INTERESSE}

Este projeto foi parcialmente financiado por Laserscope ${ }^{\circledR}$ (San Jose, Califórnia, EUA) com a quantia de US\$25.000,00, em depósito direto no ARC\# 08060, RPC\# 07745 (Inderbir Singh Gill, M.D.), Departamento de Urologia/Minimally Invasive Surgical Center - Cleveland Clinic (Cleveland, Ohio, EUA). 
Esta tese está de acordo com as seguintes normas, em vigor no momento desta publicação:

Referências: adaptado de International Committee of Medical Journals Editors (Vancouver)

Universidade de São Paulo. Faculdade de Medicina. Serviço de Biblioteca e Documentação. Guia de apresentação de dissertações, teses e monografias. Elaborado por Anneliese Carneiro da Cunha, Maria Julia de A. L. Freddi, Maria F. Crestana, Marinalva de Souza Aragão, Suely Campos Cardoso, Valéria Vilhena. $2^{\mathrm{a}}$ ed. São Paulo: Serviço de Biblioteca e Documentação; 1005.

\section{Abreviaturas dos títulos de periódicos de acordo com List of Journals Indexed in Index Medicus}




\section{SUMÁRIO}

Lista de Abreviaturas, Símbolos e Siglas

Lista de Tabelas

Lista de Gráficos

RESUMO

SUMMARY

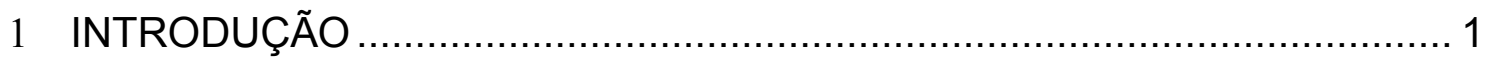

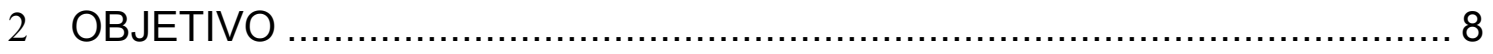

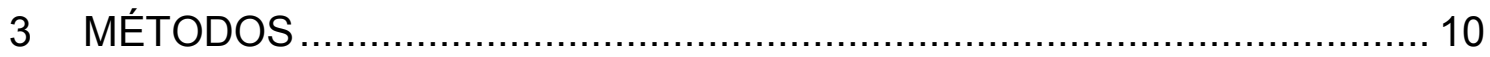

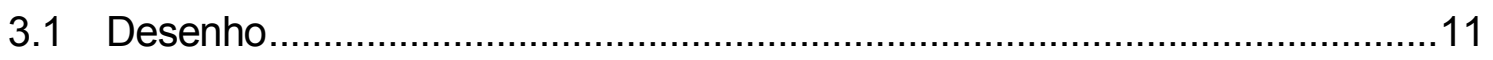

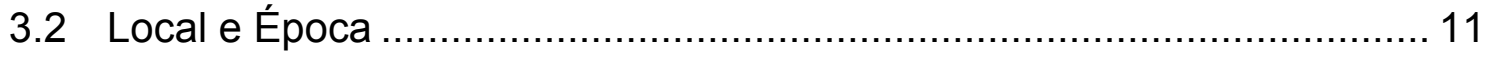

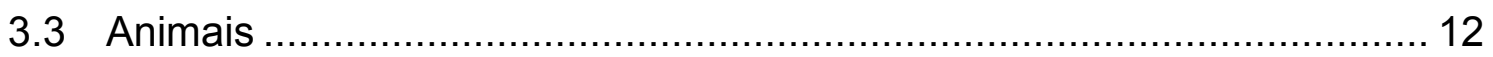

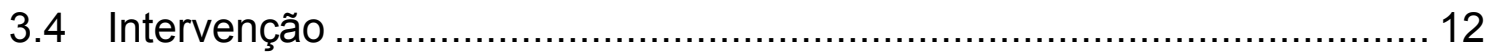

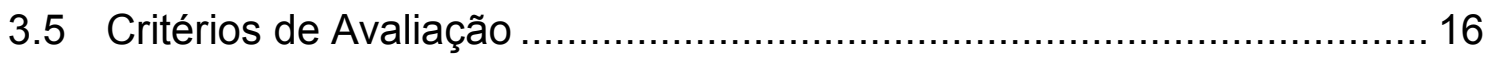

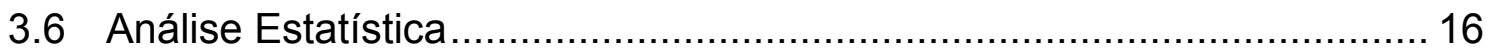

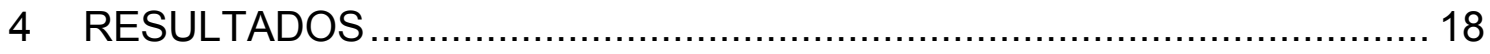

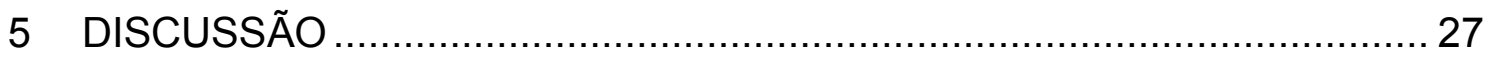

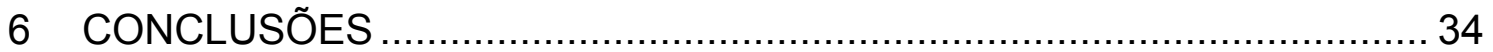

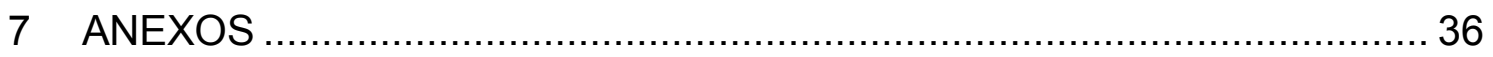

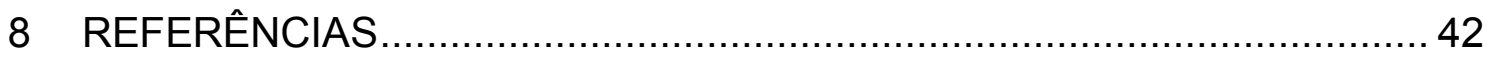




\section{LISTA DE ABREVIATURAS, SÍMBOLOS E SIGLAS}

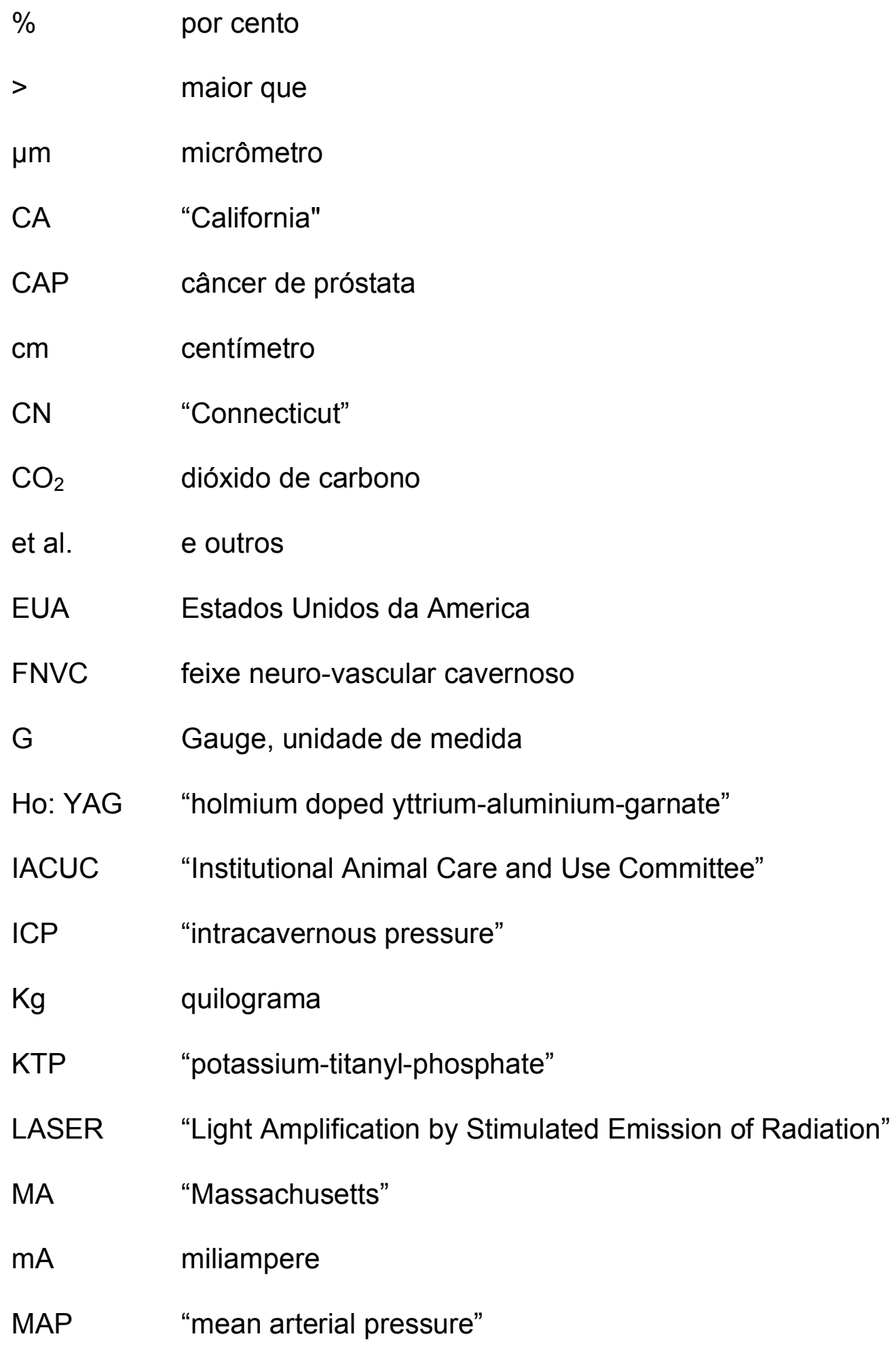




$\begin{array}{ll}\mathrm{mg} & \text { miligrama } \\ \mathrm{min} & \text { minuto } \\ \mathrm{mL} & \text { mililitro } \\ \mathrm{mm} & \text { milímetro } \\ \mathrm{Nd}: \text { YAG } & \text { "neodymium doped yttrium-aluminium-garnate" } \\ \mathrm{NJ} & \text { "New Jersey" } \\ \mathrm{nm} & \text { nanômetro } \\ \mathrm{NVB} & \text { "neurovascular bundle" } \\ { }^{\circ} \mathrm{C} & \text { grau centígrado } \\ \text { PAM } & \text { pressão arterial média } \\ \text { PIC } & \text { pressão intra-cavernosa } \\ \text { PIC/PAM } & \text { relação entre pressão intra-cavernosa e pressão arterial média } \\ \text { PSA } & \text { "prostate-specific antigen" } \\ \text { SAS } & \text { "Statistical Analysis System" } \\ \text { W } & \text { Watts }\end{array}$




\section{LISTA DE TABELAS}

Tabela 1. Resposta à neuroestimulação avaliando a relação da pressão intracavernosa e pressão arterial média (PIC/PAM) após a dissecção laparoscópica do feixe neuro-vascular cavernoso utilizando-se o bisturi ultrasônico (BU), laser KTP (KTP) e tesoura e clipes (TC) ...24

Tabela 2. Avaliação da lesão tecidual e termográfica utilizando-se o bisturi ultrasônico (BU) e laser KTP (KTP) ...........................................25 


\section{LISTA DE GRÁFICOS}

Gráfico 1. Tempo de dissecção do feixe neuro-vascular cavernoso utilizando-se o bisturi ultrasônico (BU), laser KTP (KTP) e tesoura e clipes (TC)

Gráfico 2. Perda de sangue estimada utilizando-se o bisturi ultrasônico (BU), laser KTP (KTP) e tesoura e clipes (TC) 20

Gráfico 3. Análise funcional aguda da relação da pressão intra-cavernosa e pressão arterial média (PIC/PAM) após a neuroestimulação, utilizando-se o bisturi ultrasônico (BU), laser KTP (KTP) e tesoura e clipes (TC)

Gráfico 4. Análise funcional crônica da relação da pressão intra-cavernosa e pressão arterial média (PIC/PAM) após a neuroestimulação, utilizando-se o bisturi ultrasônico (BU), laser KTP (KTP) e tesoura e clipes (TC) 23 


\section{RESUMO}

Colombo JR Jr. Efeitos do laser KTP na dissecção laparoscópica do feixe neurovascular cavernoso em modelo experimental canino [Tese]. São Paulo. Faculdade de Medicina, Universidade de São Paulo; 2008.

Introdução: A energia elétrica e ultrasônica são utilizadas com freqüência na prostatectomia radical laparoscópica e podem lesar os nervos cavernosos adjacentes através da dissipação térmica. Em contrapartida, a energia laser tem potencial para proporcionar uma dissecção precisa, com boa hemostasia e pequena lesão dos tecidos adjacentes. Este estudo avalia o efeito do laser KTP na dissecção laparoscópica do feixe neuro-vascular cavernoso em modelo experimental canino. Material e Métodos: Um total de 36 cães foi dividido igualmente em três grupos. Realizou-se a dissecção unilateral do feixe neurovascular cavernoso utilizando (1) laser KTP (KTP), (2) bisturi ultrasônico (BU), e (3) tesoura e clipes metálicos (TC), mantendo o lado contralateral intacto. Realizou-se a análise do tempo operatório e sangramento em cada grupo, assim como a análise funcional, através do coeficiente entre a pressão intracavernosa e pressão arterial média (PIC/PAM) durante a estimulação do feixe neurovascular cavernoso. Metade dos animais de cada grupo foi mantida viva por 30 dias e submetidos à nova neuroestimulação. Foram avaliados ainda os efeitos da dissipação térmica através da análise termográfica em fragmentos de peritôneo parietal e a extensão histológica da necrose tecidual na fáscia 
prostática desde a superfície de corte de cada instrumento. Resultados: O tempo de dissecção do feixe neuro-vascular cavernoso foi similar entre os grupos (KTP vs. BU $p=0.21, \mathrm{KTP}$ vs. TC $p=0.81, \mathrm{BU}$ vs. TC $p=0.22$ ). A dissecção utilizando o $\mathrm{BU}$ resultou em um prejuízo significativo na resposta à neuroestimulação quando comparado aos grupos TC e KTP no experimento agudo (BU vs. KTP $p<0.001$, BU vs. TC $p<0.001$ ), e crônico (BU vs. KTP $p=0.02$, $\mathrm{BU}$ vs. TC $p=0.02)$. A análise histológica demonstrou uma área de necrose desde a superfície de corte com a utilização do laser KTP de aproximadamente $500 \mu \mathrm{m}$, enquanto que com o uso do BU essa área se extendeu em média por 2 mm. A avaliação termográfica mostrou uma dissipação térmica significativamente maior do BU comparado ao laser KTP (laser KTP 0.98 mm vs. BU $6.25 \mathrm{~mm}, p<0.0001)$. Conclusão: $\mathrm{O}$ uso do laser KTP na dissecção laparoscópica do feixe neuro-vascular cavernoso apresentou resultado funcional semelhante à técnica sem emprego de energia térmica utilizando tesoura e clipes, enquanto o bisturi ultrasônico foi associado a um prejuízo significativo na função dos nervos cavernosos.

\author{
Descritores: 1.Laser 2.Laparoscopia 3.Modelos animais 4. Análise de \\ resultados (cuidados de saúde)
}




\section{SUMMARY}

Colombo Júnior JR. Effect of KTP laser in the laparoscopic dissection of the cavernous neurovascular bundles [Thesis]. São Paulo. Faculdade de Medicina, Universidade de São Paulo; 2008.

Introduction: Electrical and ultrasonic energy used in nerve-sparing laparoscopic radical prostatectomy can compromise cavernous nerve function. Laser energy may potentially allow fine dissection with good hemostasis and minimal adjacent tissue injury. This study examines the electrophysiological, histological and thermal mapping features of KTP laser dissection on cavernous nerve function in the survival canine model. Materials and Methods: A total of 36 dogs were divided into 3 groups. Laparoscopic unilateral neurovascular bundle (NVB) mobilization was performed using either: (1) KTP laser $(n=12),(2)$ ultrasonic shears (US) $(n=12)$, or (3) athermally with cold scissors (AT) $(n=12)$. The contralateral NVB remained undissected as an internal control. NVB function was assessed acutely in all dogs, and after 1-month survival in $50 \%$ of the dogs of each group. Peak intracavernosal pressure response to cavernous nerve stimulation was measured as a percentage of mean arterial pressure (ICP/MAP). Strips of peritoneum were sectioned ex-vivo with the KTP laser and US shears for thermographic mapping. Histological evaluation of prostatic fascia necrosis from the cutting surface was also performed. Results: Comparing KTP and AT 
groups, the erectile response to nerve stimulation was similar acutely and at 1 month (acute ICP/MAP: KTP 92\%, AT 96\% p=0.54; chronic ICP/MAP: KTP 95\%, AT $98 \% p=0.71)$. In contrast, US dissection resulted in a significant decrease in the ICP response compared to the KTP and AT groups (acute ICP/MAP: US $49 \%$, KTP 92\%, AT 96\%. US vs. KTP $p<0.001$, US vs. AT $p<0.001$; chronic ICP/MAP: US 58\%, KTP 95\%, AT 98\%, US vs. KTP $p=0.02$, US vs. AT $p=0.02$ ). Mean NVB dissection times were similar (KTP 27.5min, US 19.9min, AT 26.6min, KTP vs. US $p=0.21$, KTP vs. AT $p=0.81$, US vs. AT $p=0.22$ ). Histopathology demonstrated an acute zone of laser-induced necrosis of approximately $500 \mu \mathrm{m}$ compared to $2 \mathrm{~mm}$ with US dissection. Thermographic assessment demonstrated significantly less collateral thermal spread from the KTP laser compared to US (mean thermal spread $>60{ }^{\circ} \mathrm{C}$ KTP $0.98 \mathrm{~mm}$ vs. US $6.25 \mathrm{~mm}$, $p<0.0001)$. Conclusions: Use of KTP laser for NVB mobilization preserved cavernous nerve function comparable to standard athermal techniques using cold scissors and was superior to ultrasonic shears.

Descriptors: 1.Lasers 2.Laparoscopy 3.Models, animals 4.Outcome assessment (health care) 
Introdução 
O câncer de próstata (CAP) é a doença maligna mais diagnosticada em homens no Brasil excetuando-se tumores de pele não-melanoma, sendo a segunda causa de óbitos entre as neoplasias malignas, com taxa de mortalidade de 9,66 por 100.000 habitantes ${ }^{1}$. Segundo dado do Instituto Nacional de Câncer estima-se que 47.280 casos novos foram diagnosticados no ano de 2006 no país ${ }^{1}$. Mundialmente, a neoplasia prostática também é a mais prevalente em homens, com 220.900 casos novos diagnosticados somente nos Estados Unidos da América em 2003, com 28.900 óbitos no mesmo período ${ }^{2}$.

O tratamento do CAP é baseado no estadiamento da doença e opção do paciente, abrangendo um espectro que engloba acompanhamento clínico (watchful waiting, active surveillance), cirurgia, radioterapia externa ou braquiterapia (implantação de sementes radioativas), crioterapia e bloqueio androgênico (químico ou cirúrgico). A utilização do exame de PSA, associado ao exame físico periódico preventivo, aumentou a detecção de tumores restritos à próstata, sendo estes passíveis de cura ${ }^{3}$.

Até o momento, o tratamento cirúrgico do câncer de próstata localizado, realizado através da prostatectomia radical, é a única forma de tratamento que comprovadamente mostrou a redução da mortalidade específica e global, assim como redução dos riscos de progressão da doença em estudo controlado e randomizado ${ }^{3}$. Inicialmente descrita em 1905 por Young ${ }^{4}$ utilizando-se o acesso perineal, e em 1949 por Mermmelaar e Millin ${ }^{5}$ com o acesso retropúbico, a técnica cirúrgica da prostatectomia radical evoluiu devido a novos estudos 
anatômicos e funcionais, recebendo atualmente a nomenclatura de prostatectomia radical anatômica desde o estudo publicado por Reiner e Walsh em $1979^{6}$.

O conhecimento anatômico e fisiológico do sistema reprodutor masculino revelou a importância da integridade dos nervos cavernosos no mecanismo da ereção. Este fato viabilizou a evolução técnica da prostatectomia radical, introduzindo o conceito da preservação do feixe neuro-vascular cavernoso (FNVC) durante o procedimento, podendo a preservação ser bilateral ou unilateral, de acordo com as características clínico-patológicas de cada indivíduo. Localizado em íntimo contato com a superfície póstero-lateral da próstata, e de natureza delicada, o FNVC pode ser lesado de maneira iatrogênica durante sua dissecção ${ }^{7-9}$.

As principais complicações da prostatectomia radical são a incontinência urinária e a disfunção erétil, ambas apresentando incidência com grande variação na literatura, resultado de diferentes definições, seleção de pacientes, experiência do cirurgião, volume de casos operados e maneira de coleta de dados utilizada nos estudos publicados ${ }^{10}$. A disfunção erétil pós-prostatectomia radical é multifatorial, e tem como principal origem a causa neurogênica, devido a lesão dos nervos cavernosos durante a dissecção do FNVC, podendo estar ainda associado a origem vasculogênica e/ou psicogênica ${ }^{10}$. Embora seu tratamento tenha sido facilitado pela introdução de drogas inibidoras da 5fosfodiesterase de uso oral e intracavernosa, ainda é grande o impacto da disfunção erétil na qualidade de vida dos pacientes submetidos à prostatectomia 
radical, com taxas de preservação da potência nesta população variando de $10 \%$ a $90 \%{ }^{11-13}$.

A técnica minimamente invasiva através do acesso laparoscópico para a prostatectomia radical foi inicialmente descrita por Guillonneau e Vallancien em $1999^{14}$, e a utilização de um sistema robótico para a execução da técnica robôassistida ocorreu em $2000^{15,16}$. Da mesma forma que a cirurgia convencional, a prostatectomia radical minimamente invasiva apresenta variações técnicas, com diferentes abordagens descritas: transperitoneal descendente com dissecção inicial das vesículas seminais, transperitoneal descendente sem dissecção inicial das vesículas seminais, transperitoneal ascendente, extraperitoneal ascendente e extraperitoneal descendente ${ }^{17}$. Embora existam vantagens e desvantagens em todas as abordagens citadas, acredita-se que a experiência do cirurgião seja o fator mais importante no critério de escolha ${ }^{17}$. Apesar de mais recente e com resultados em longo prazo ainda não amplamente disponíveis, estudos mostram que a abordagem minimamente invasiva apresenta resultados oncológicos e funcionais semelhantes a técnica convencional, com benefício na morbidade perioperatória ${ }^{18}$.

A magnificação de imagem durante o acesso laparoscópico permitiu um ganho científico adicional da neuroanatomia do FNVC, contribuindo para a técnica de preservação do mesmo. Na busca de maior precisão e exata identificação intraoperatória do FNVC, alguns recursos foram descritos: utilização da estimulação nervosa, levando a confirmação anatômica através do diâmetro peniano, variação de pressão intracavernosa e/ou intra-uretral ${ }^{19-21}$, e a 
utilização do ultrassonografia transretal com Doppler intraoperatória, permitindo a visualização anatômica baseada no fluxo arterial das artérias cavernosas ${ }^{22}$.

Embora o emprego de formas de energia durante a dissecção do FNVC no acesso retropúbico tenha sido minimizado com a evolução da técnica cirúrgica, no acesso laparoscópico e robô-assistido ainda é comum o uso de eletrocautério mono e/ou bipolar, e energia ultrasônica, associado a clipes hemostáticos ${ }^{18,22}$. Acredita-se que o uso de energia térmica prejudique a função erétil pós-operatória, sendo o principal mecanismo a lesão nervosa secundária a dissipação da energia térmica gerada por estes dispositivos ${ }^{22-24}$.

Estudos demonstraram que a lesão térmica das fibras nervosas inicia-se partir de uma temperatura próxima a $60^{\circ} \mathrm{C}$, afetando tanto as fibras nãomielínicas como as mielínicas ${ }^{25-27}$. Carlander et al mostrou que durante sua utilização clínica, a ponta dos instrumentos ultrasônicos e eletrocautério atingem uma temperatura ao redor de $150{ }^{\circ} \mathrm{C}$ e $400{ }^{\circ} \mathrm{C}$ respectivamente, com o último causando maior dano secundário a estruturas nervosas adjacentes ${ }^{28}$. Ong et al analisou o impacto na função dos nervos cavernosos da energia elétrica monopolar, bipolar e bisturi ultrasônico utilizadas na dissecção do FNVC durante a prostatectomia radical aberta, e concluiu neste estudo que ocorre um prejuízo funcional significativo associado a utilização destas fontes de energia térmica durante o procedimento ${ }^{23}$.

Neste contexto, a energia do feixe de laser (light amplification by stimulated emission of radiation) pode potencialmente proporcionar uma dissecção rápida e precisa, com hemostasia adequada e mínima lesão aos 
tecidos adjacentes ${ }^{29}$. Com sua ação inicialmente descrita por Albert Einstein em $1917^{30}$, o primeiro laser ativo foi criado em 1960 por Maiman ${ }^{31}$, e utilizado no tratamento de lesões cutâneas em $1964{ }^{32}$. O feixe de laser tem três características únicas: (1) feixe com mesmo comprimento de onda (feixe monocromático), (2) feixe de ondas coerentes (em fase única), (3) feixe de ondas paralelas (colimado); permitindo uma transmissão eficiente e direta de alta quantidade energética através de grandes distâncias ${ }^{29}$. O estudo recentemente publicado por Gianduzzo et al utilizando o laser Nd: YAG durante a prostatectomia radical laparoscópica com preservação do feixe neuro-vascular cavernoso demonstrou que a lesão a partir da superfície de corte ocorreu com profundidade média de $687 \mu \mathrm{m}$, resultando ainda em pequena perda sanguínea durante o procedimento ${ }^{33}$.

Entre os principais tipos de laser empregados na Urologia, podemos destacar o laser $\mathrm{CO}_{2}$, laser Ho: YAG, laser $\mathrm{Nd}$ : YAG e laser KTP. O laser $\mathrm{CO}_{2}$ apresenta penetração tecidual superficial, no entanto deve ser utilizado com uma fibra rígida, fato que limita seu uso. As propriedades fotomecânicas do laser Ho: YAG (holmium doped yttrium-aluminium-garnate) (comprimento de onda de 2100 $\mathrm{nm}$ ) resulta em efeito tecidual explosivo, produzindo uma margem de corte irregular ${ }^{34}$,com potencial de disseminação de células malignas ${ }^{35}$. O laser $\mathrm{Nd}$ : YAG (neodymium doped yttrium-aluminium-garnate) (comprimento de onda de $1064 \mathrm{~nm}$ ) permite uma dissecção e hemostasia adequadas, mas geralmente produz uma lesão térmica secundária maior do que o laser KTP (potassiumtitanyl-phosphate) ${ }^{34}$. O feixe de laser KTP possui comprimento de onda de 532 
$n m$, e permite uma hemostasia adequada, com penetração tecidual superficial ${ }^{34}$. Por este motivo, o laser KTP foi selecionado para estudar a agressão sobre o feixe neuro-vascular cavernoso do cão durante a dissecção realizada através do acesso laparoscópico. 


\section{Objetivo}


Avaliar o laser KTP durante a dissecção laparoscópica do feixe neurovascular cavernoso, analisando parâmetros operatórios, lesão tecidual, dissipação térmica, e resultado funcional, comparando ao bisturi ultrasônico e a dissecção sem utilização de energia térmica em modelo experimental canino. 


\section{Métodos}




\subsection{Desenho}

Com o consentimento do comitê institucional de cuidados com animais de pesquisa (Institutional Animal Care and Use Committee - IACUC), 36 cães foram igualmente divididos em três grupos e submetidos à dissecção unilateral do feixe neuro-vascular cavernoso utilizando-se o acesso laparoscópico. No primeiro grupo (KTP) a dissecção foi realizada utilizando-se o laser KTP, no segundo grupo (TC) utilizamos apenas tesoura e clipes de titânio, e no terceiro grupo (BU) utilizamos o bisturi ultrasônico. Metade dos animais foi sacrificada imediatamente após o procedimento inicial (experimento agudo) de dissecção e estimulação do feixe neuro-vascular cavernoso, enquanto a metade restante foi submetida a nova neuroestimulação utilizando-se o acesso convencional 30 dias após a intervenção cirúrgica inicial (experimento crônico).

\section{$3.2 \quad$ Local e Época}

O estudo em questão foi realizado nas instalações do Centro de Cirurgia Minimamente Invasiva da Cleveland Clinic, localizado na cidade de Cleveland, estado de Ohio, nos Estados Unidos da América, no período de 07 de Março a 19 de Setembro de 2006. 


\subsection{Animais}

Um total de 36 cães machos adultos de diferentes raças com peso entre 25 e $35 \mathrm{~kg}$ foram utilizados no estudo. Previamente ao início do estudo, cinco animais foram utilizados para dissecção, estudo da anatomia neuro-vascular periprostática e refinamento do procedimento cirúrgico.

\subsection{Intervenção}

Cirurgia: Após um período de 6 horas de jejum, os animais receberam $1 \mathrm{~g}$ endovenoso de Cefazolina profilático e foram anestesiados com $20 \mathrm{mg} / \mathrm{kg}$ de Tiopental endovenoso e Isofluorane a $0.5-2.5 \%$ por via inalatória, sendo mantidos sob intubação oro-traqueal e ventilação assistida. Realizou-se então uma incisão peno-escrotal mediana e exposição dos corpos cavernosos, onde foi introduzido um cateter de $21 \mathrm{G}$ para aferição da pressão intra-cavernosa. Um cateter semelhante foi introduzido por via percutânea na artéria femoral direita para aferição da pressão arterial. Ambos os cateteres foram conectados a sensores de pressão, através de equipo estéril preenchido com solução fisiológica contendo 10,000 U de heparina por litro.

Após a antisepsia do abdômen e colocação de panos estéreis, um trocarte de $10 \mathrm{~mm}$ foi posicionado na cavidade abdominal através de incisão infra-umbelical de $2 \mathrm{~cm}$ e acesso cirúrgico direto até o espaço peritoneal, 
estabelecendo-se o pneumoperitôneo com dióxido de carbono $\left(\mathrm{CO}_{2}\right)$ a uma pressão de $15 \mathrm{mmHg}$. Sob visão direta utilizando-se uma câmera de $30^{\circ}$, cinco outros trocartes foram introduzidos na cavidade abdominal, dois trocartes de 10 $\mathrm{mm}$, dois trocartes de $5 \mathrm{~mm}$ e um trocarte de $2 \mathrm{~mm}$ conforme mostrado na Figura 1.

Após realizar a inspeção da cavidade abdominal e pélvica, realizou-se a exposição prostática através de dissecção romba com o aspirador, sem utilização de energia elétrica/ultrasônica. Um ponto de Vicryl-0 com agulha CT-1 transfixou a base prostática, com o intuito de facilitar a apresentação do órgão durante o procedimento. Após a identificação da fáscia prostática lateral, o FNVC foi estimulado utilizando-se o probe laparoscópico do neuroestimulador Cavermap $^{\circledR}$ (Bluetorch Medical Products, MA, EUA), inicialmente utilizando $2 \mathrm{~mA}$ e então este valor foi dobrado a cada 20 segundos até o máximo de $8 \mathrm{~mA}$ por um tempo mínimo de 80 segundos. A pressão intracavernosa foi armazenada na forma absoluta e como porcentagem da pressão arterial sistêmica média (PIC/PAM).

O FNVC esquerdo foi mobilizado completamente desde a base até o ápice prostático, utilizando-se tesoura e clipes metálicos, bisturi ultrasônico ou laser KTP, de acordo com o grupo estudado. O FNVC não foi dissecado a direita, servindo como controle.

A dissecção com o laser KTP foi realizada utilizando o aparelho Aura $\mathrm{XP}^{\mathrm{TM}}$ (Laserscope, CA, EUA) com potência de $6 \mathrm{~W}$, através de uma fibra Endostat $^{\mathrm{TM}}$ de $200 \mu \mathrm{m}$ que foi introduzida com uma pinça de $2 \mathrm{~mm}$ desenhada 
especificamente para essa função. Durante a dissecção, a fáscia prostática foi apreendida delicadamente com uma pinça laparoscópica tipo Kelly e o laser ativado a uma distância de 3 a $5 \mathrm{~mm}$ desde a ponta da fibra até a superfície a ser seccionada (Figura 2). Durante o período de dissecção, a equipe cirúrgica, anestésica e de apoio em sala operatória usavam óculos de proteção para evitar acidentes em casos de ruptura da fibra durante sua ativação.

A dissecção com o bisturi ultrasônico foi realizada utilizando-se o aparelho Harmonic $\mathrm{ACE}^{\mathrm{TM}}$ (Ethicon Endo-Surgery, NJ, EUA) com potência de cinco. O modo de corte foi utilizado para a realização da dissecção e hemostasia. A lâmina inativa foi introduzida entre a próstata e o feixe neurovascular, fechando-se o instrumento e acionando-o com uma leve tração até o corte do tecido. O instrumento também foi usado para dissecção romba, da mesma forma que ocorre na prática clínica.

A dissecção sem utilização de energia térmica realizada com tesoura e clipes metálicos foi executada com Endoshears (Auto Suture, Norwalk, CN, EUA) e clipes de titânio de $5 \mathrm{~mm}$. A fáscia lateral foi incisada e o plano entre a fáscia e a próstata foi encontrado através da dissecção romba. A fáscia foi então progressivamente ligada com clipes metálicos e seccionada com a tesoura, mobilizando-a amplamente desde a base até o ápice prostático. A estimulação do FNVC foi repetida bilateralmente após a dissecção da maneira previamente descrita.

Nos animais que seriam submetidos a um novo procedimento, as incisões dos trocartes de $10 \mathrm{~mm}$ foram fechadas com fio absorvível em dois planos, 
enquanto as incisões dos trocartes de 2 e $5 \mathrm{~mm}$ foram fechadas em plano único. Após o procedimento cirúrgico, os animais foram transferidos para o biotério, permanecendo sob constante supervisão dos investigadores e veterinários responsáveis pelo estudo. Após 30 dias, os animais foram novamente anestesiados e preparados conforme previamente descrito e, através de uma laparotomia mediana, submetidos à nova neuroestimulação do FNVC. Ao final dos experimentos, antes do sacrifício dos animais, a bexiga, próstata e tecidos periprostático foram retirados em bloco e os cães então sacrificados com injeção intravenosa de cloreto de potássio.

Em dois cães, foram retirados 12 fragmentos de peritôneo parietal e então estes fragmentos foram seccionados utilizando-se o laser KTP e o bisturi ultrasônico, para a análise termográfica. Assim como no restante do estudo, utilizou-se o laser KTP com potência de $6 \mathrm{~W}$ e o bisturi ultrasônico com modo de corte com ajuste em cinco. A dissipação térmica foi gravada utilizando-se uma termo-câmera (ThermoVision A40M, FLIR Systems, Boston, MA, EUA) e as imagens foram posteriormente analisadas com o programa ThermaCAM Researcher pro 2.8 SR-1. Os dados termográficos da secção do peritôneo utilizando os dois instrumentos foram comparados, assim como a distribuição da temperatura na ponta de cada instrumento e o tempo desde o término da ativação até atingir uma temperatura menor que $60^{\circ} \mathrm{C}$.

Histologia: os espécimes cirúrgicos foram fixados em formalina a 10\%, seccionadas transversalmente na base, região média e ápice prostático, sendo corados com eosina e hematoxilina. 


\subsection{Critérios de Avaliação}

Os três grupos foram avaliados utilizando-se parâmetros operatórios, funcionais, termográficos e histológicos:

Os parâmetros operatórios avaliados foram tempo de dissecção do FNVC e perda sanguínea intra-operatória estimada através da quantidade de sangue aspirada durante o procedimento.

A avaliação funcional foi realizada empregando-se a neuroestimulação do FNVC conforme já descrito anteriormente. Avaliamos o coeficiente entre a pressão intra-cavernosa e a pressão arterial média (PIC/PAM) no experimento agudo (primeiro procedimento), assim como no experimento crônico (após 30 dias).

A análise termográfica avaliou a dispersão térmica durante a utilização do laser KTP e bisturi ultrasônico, assim como o tempo que a extremidade de cada instrumento levou até atingir a temperatura de $60^{\circ} \mathrm{C}$.

A avaliação histológica mensurou a extensão da necrose tecidual desde a superfície de corte obtida por cada instrumento.

\subsection{Análise Estatística}

A análise estatística foi realizada utilizando a versão comercial disponível do programa JMP (JMP 6.0.2, SAS Institute Inc. 2006, NC - EUA). Para 
variáveis contínuas e distribuição normal utilizou-se o teste t de Student, e para variáveis contínuas e distribuição não-normal utilizou-se o teste Wilcoxon Rank Sum. Todos os testes foram bicaudais e considerados significantes quando $p<0.05$. 
Resultados 


\section{Análise operatória: tempo operatório}

O tempo de dissecção do FNVC [mediana] foi de 29 min (6 - 42) no grupo KTP, $25 \min (17$ - 35) no grupo TC, e $15 \min (5$ - 50) no grupo BU, respectivamente (Gráfico 1). A comparação entre os grupos não mostrou diferença significativa (KTP vs. TC $p=0.71$; KTP vs. BU $p=0.14 ;$ TC vs. BU $p=0.09)$.

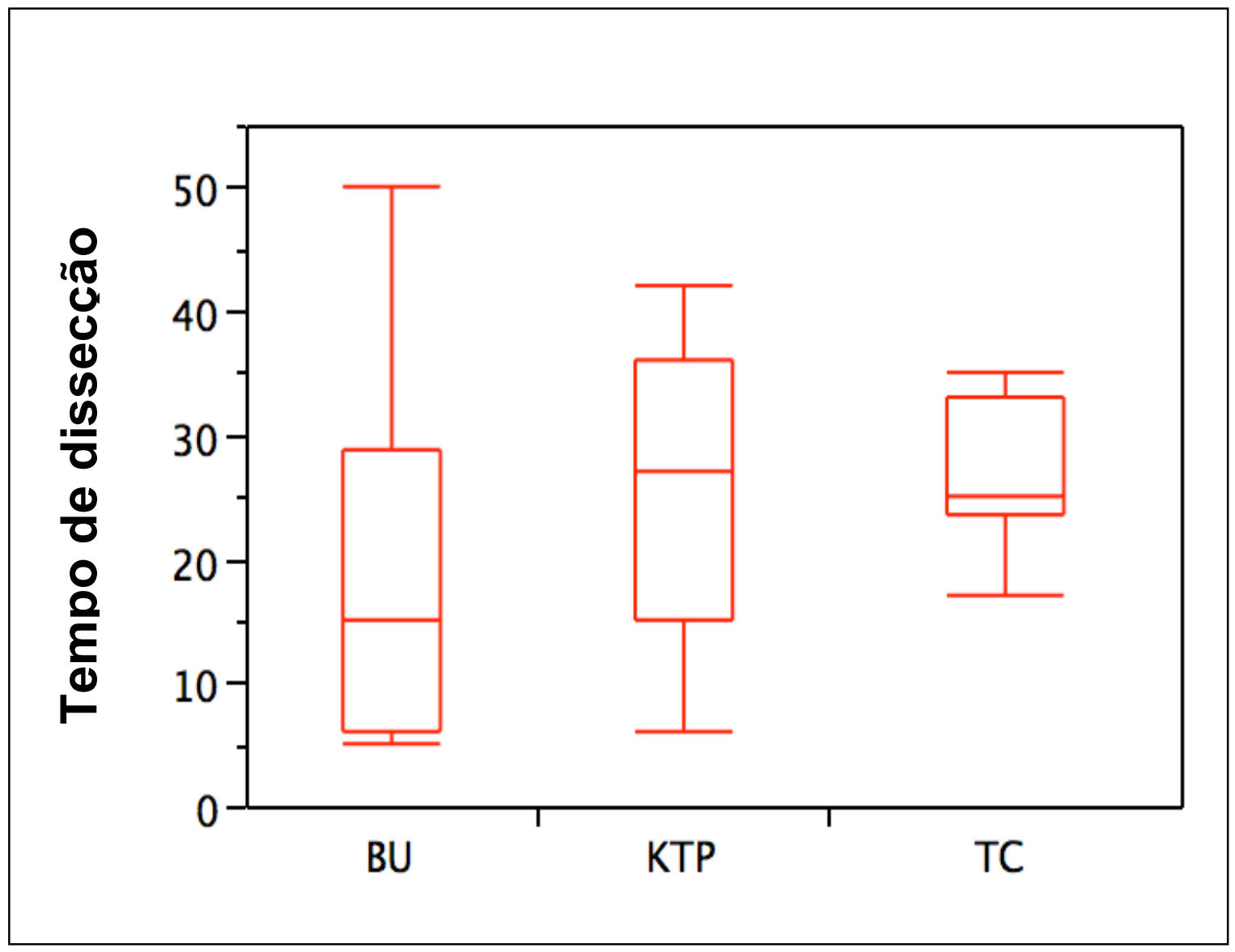

Gráfico 1. Tempo de dissecção do feixe neuro-vascular cavernoso utilizandose o bisturi ultrasônico (BU), laser KTP (KTP) e tesoura e clipes (TC)

TC vs. KTP $p=0.71 ; \mathrm{KTP}$ vs. $\mathrm{BU} p=0.14 ; \mathrm{TC}$ vs. $\mathrm{BU} p=0.09$ 


\section{Análise operatória: perda de sangue}

A perda de sangue estimada [mediana] encontrada foi de $10 \mathrm{~mL}(0-25)$ no grupo KTP, $20 \mathrm{~mL}(5$ - 100) no grupo TC, e de $8 \mathrm{~mL}(0-50)$ no grupo BU, respectivamente (Gráfico 2). Comparando o grupo TC com os grupos restantes encontramos uma diferença significativa no sangramento intra-operatório (TC vs. KTP $p=0.028$, TC vs. BU $p=0.007)$. Não houve diferença entre os grupos KTP e BU neste parâmetro $(p=0.91)$.

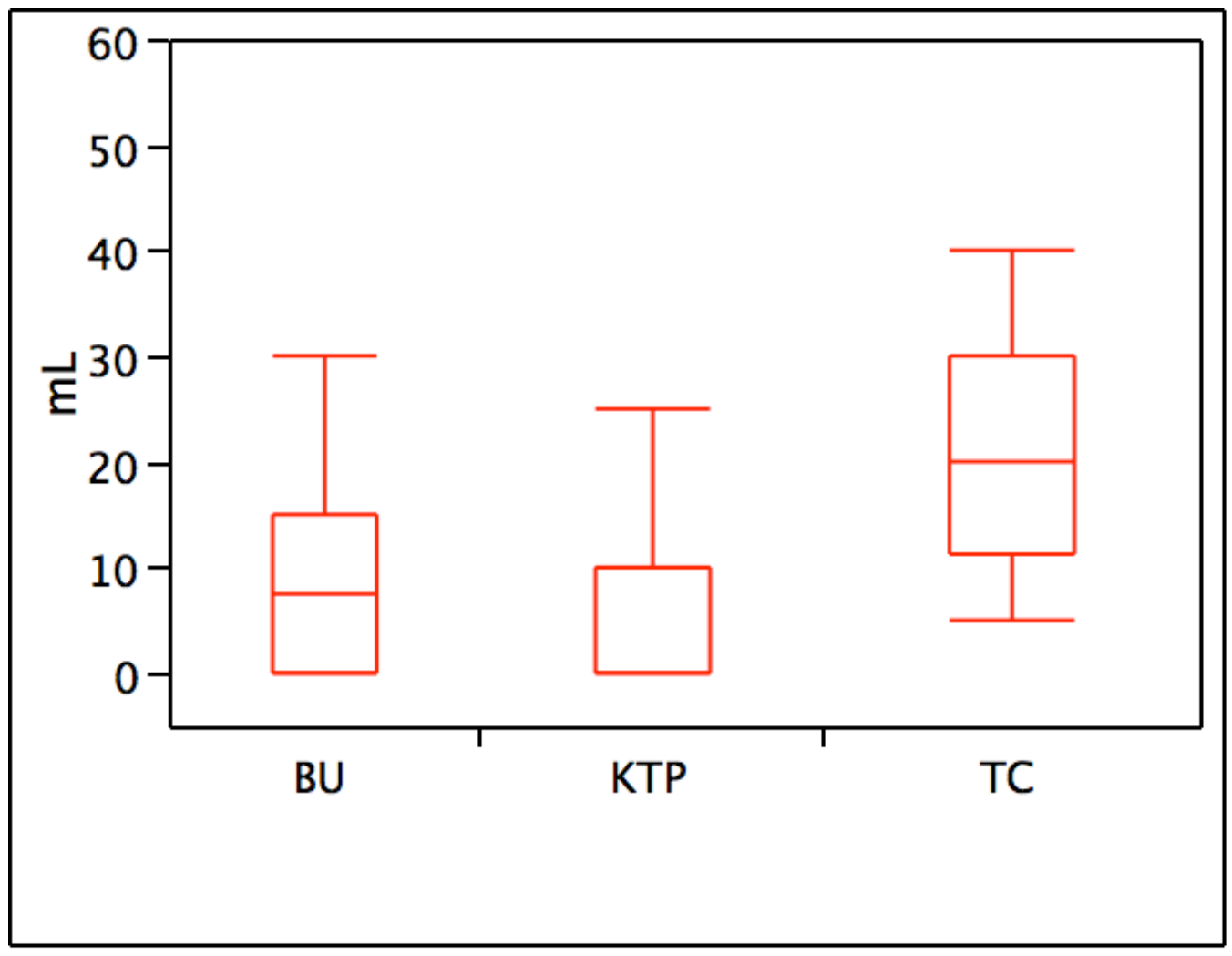

Gráfico 2. Perda de sangue estimada utilizando-se o bisturi ultrasônico (BU), laser KTP (KTP) e tesoura e clipes (TC)

$\underline{\mathrm{TC}}$ vs. KTP $p=0.028 ; \mathrm{KTP}$ vs. BU $p=0.91 ; \underline{\mathrm{TC}}$ vs. BU $p=0.007$ 


\section{Análise funcional}

Durante o experimento agudo, a mediana do coeficiente PIC/PAM com a neuroestimulação imediatamente após a dissecção do FNVC foi de 92\% (61\% $107 \%)$ no grupo KTP, $98 \%(61 \%$ - $126 \%)$ no grupo TC, e $53 \%(20 \%-86 \%)$ no grupo BU, respectivamente (Gráfico 3). Comparando o coeficiente PIC/PAM do lado dissecado com o lado controle, foi encontrada uma diferença significativa no grupo BU $(p<0.001)$, enquanto que nos grupos TC $(p=0.98)$ e KTP $(p=0.70)$ a resposta funcional foi similar em ambos os lados.

No experimento crônico (Gráfico 4), o coeficiente PIC/PAM com a neuroestimulação foi de $98 \%(84 \%$ - 102\%) no grupo KTP, 100\% (69\% - 123\%) no grupo TC, e 56\% (21\% - 93\%) no grupo BU, respectivamente (Tabela 1). Comparando o coeficiente PIC/PAM do lado dissecado com o lado controle encontrou-se uma diferença significativa novamente apenas no grupo BU $(p=0.01)$, enquanto que nos grupos $\operatorname{KTP}(p=0.42)$ e TC $(p=0.83)$ a resposta funcional foi mais uma vez semelhante em ambos os lados.

Não houve diferença significativa entre os grupos KTP e TC tanto no experimento agudo $(p=0.51)$ quanto no experimento crônico $(p=0.38)$. No entanto, o grupo BU apresentou uma resposta a neuroestimulação inferior em ambos os experimentos quando comparado ao grupo TC (agudo $p<0.001$; crônico $p=0.013$ ) e ao grupo KTP (agudo $p<0.001$; crônico $p=0.016$ ). 


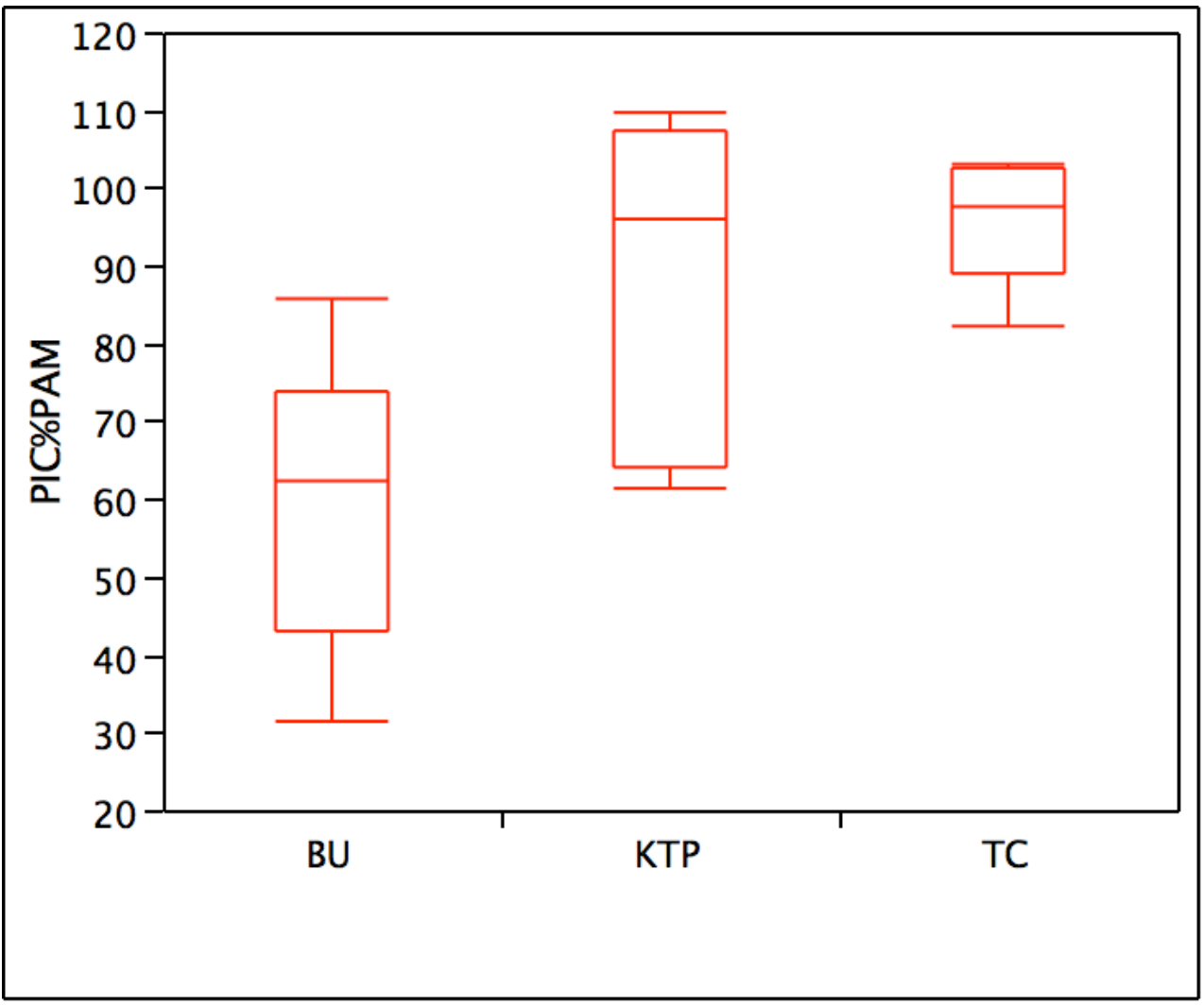

Gráfico 3. Análise funcional aguda da relação da pressão intra-cavernosa e pressão arterial média (PIC/PAM) após a neuroestimulação, utilizando-se o bisturi ultrasônico (BU), laser KTP (KTP) e tesoura e clipes (TC)

TC vs. KTP $p=0.51 ; \underline{\text { KTP vs. BU } p<0.001 ; \text { TC vs. BU } p<0.001}$ 


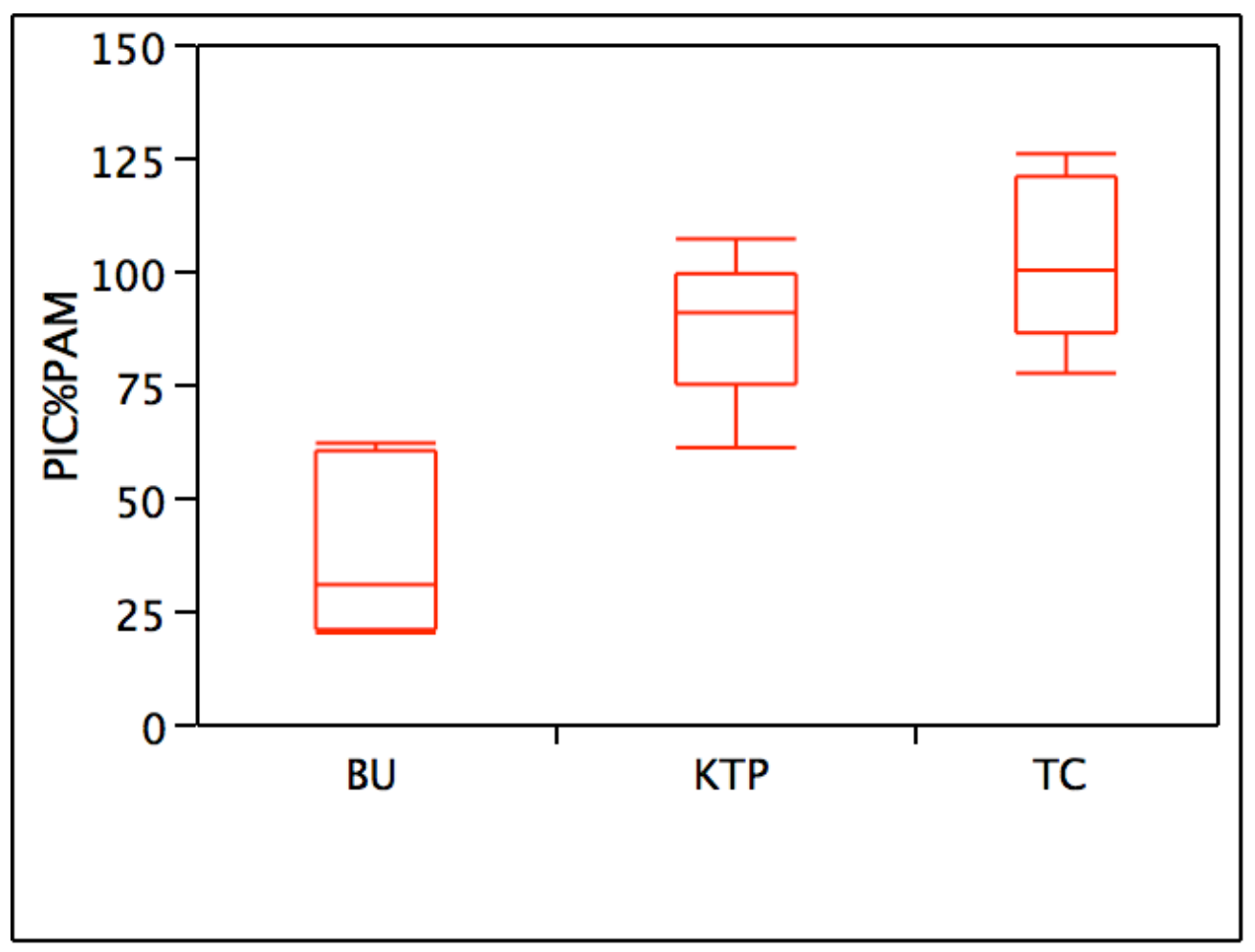

Gráfico 4. Análise funcional crônica da relação da pressão intra-cavernosa e pressão arterial média (PIC/PAM) após a neuroestimulação, utilizando-se o bisturi ultrasônico (BU), laser KTP (KTP) e tesoura e clipes (TC)

TC vs. KTP $p=0.38 ; \underline{\text { KTP vs. } \mathrm{BU} p=0.016 ; \mathrm{TC} \text { vs. } \mathrm{BU} p=0.013}$ 
Tabela 1. Resposta à neuroestimulação avaliando a relação da pressão intracavernosa e pressão arterial média (PIC/PAM) após a dissecção laparoscópica do feixe neuro-vascular cavernoso utilizando-se 0 bisturi ultrasônico (BU), laser KTP (KTP) e tesoura e clipes (TC)

PIC/PAM

Agudo (\%) Crônico (\%) p value

\begin{tabular}{|c|c|c|c|}
\hline BU & $53(20-86)$ & $56(21-93)$ & $\begin{array}{l}p<0.001^{*} \\
p<0.05^{* *}\end{array}$ \\
\hline KTP & $93(61-107)$ & $98(84-102)$ & NS \\
\hline TC & $98(61-126)$ & $100(69-123)$ & NS \\
\hline
\end{tabular}




\section{Análise termográfica}

O mapeamento termográfico da incisão de peritôneo parietal mostrou uma maior dissipação de calor do bisturi ultrasônico em relação ao laser KTP. Durante as secções de tecido, o calor dissipado $\left(>60^{\circ} \mathrm{C}\right)$ desde a superfície de corte atingiu $0.98 \mathrm{~mm}$ com o laser KTP $(p<0.001)$ e $6.25 \mathrm{~mm}$ com o bisturi ultrasônico, respectivamente (Figura 3 e 4). A temperatura na extremidade da fibra do laser KTP levou três segundos até atingir uma temperatura inferior a 60 ${ }^{\circ} \mathrm{C}$, enquanto no bisturi ultrasônico esse tempo foi de 40 segundos (Tabela 2).

Tabela 2. Avaliação da lesão tecidual e termográfica utilizando-se o bisturi ultrasônico (BU) e laser KTP (KTP)

\begin{tabular}{llll}
\hline & Profundidade & $\begin{array}{l}\text { Tempo de } \\
\text { dissipação } \\
\text { térmica }\end{array}$ & $\begin{array}{l}\text { Necrose } \\
\text { tecidual }\end{array}$ \\
\hline \hline BU & $6.25 \mathrm{~mm}$ & $40^{\prime \prime}$ & $2 \mathrm{~mm}$ \\
KTP & $0.98 \mathrm{~mm}$ & $3 "$ & $500 \mu \mathrm{m}$ \\
& & & $<0.001$ \\
\hline
\end{tabular}




\section{Análise histológica}

A avaliação histológica demonstrou que a lesão necrótica média proporcionada pelo laser KTP foi de $500 \mu \mathrm{m}$ (Figura 5) desde a superfície de corte, enquanto o bisturi ultrasônico a necrose tecidual extendeu-se em média por $2 \mathrm{~mm}$ desde a superfície de corte $(p<0.001)$ (Tabela 2$)$. 


\section{Discussão}


A utilização do laser KTP na dissecção laparoscópica do feixe neurovascular cavernoso em modelo canino apresentou sangramento pequeno e mínima dissipação térmica sobre o FNVC, preservando a função dos nervos cavernosos, proporcionando assim uma maior possibilidade de recuperação da função erétil.

A preservação da função erétil ainda persiste como um dos aspectos mais desafiadores após a prostatectomia radical laparoscópica com preservação do FNVC. A manutenção da hemostasia adequada é fundamental para manter o campo operatório limpo para proporcionar a mobilização precisa da próstata, minimizando o trauma a estruturas nobres adjacentes como os nervos cavernosos. No entanto, os atuais métodos hemostáticos utilizados durante a prostatectomia radical laparoscópica prejudicam a função dos nervos cavernosos ${ }^{23}$. Ong et al mostrou em estudo experimental em cães que a utilização de energia térmica (energia elétrica monopolar, energia elétrica bipolar e bisturi ultrasônico) durante a prostatectomia radical aberta com preservação do FNVC tem prejuízo significativo tanto na fase aguda (logo após o procedimento decréscimo de $74 \%$ - 91\% na resposta à neuroestimulação) quanto na fase crônica do estudo (após 2 semanas - decréscimo de 93\% - 96\% na resposta à neuroestimulação ${ }^{23}$.

Dissecções que não empregam formas de energia térmica, independente do acesso utilizado, são tecnicamente mais complexas, sendo os clipes empregados de grande tamanho quando comparados aos vasos periprostáticos 
e frequentemente são deslocados durante subseqüente dissecção e manipulação cirúrgica. Além disso, na prostatectomia radical robótica, o cirurgião é dependente da habilidade cirúrgica do assistente na colocação dos clipes na posição desejada e, em muitos casos, a colocação dos clipes hemostáticos não é tão eficaz quanto à colocação executada pelo próprio cirurgião. Existe ainda o risco potencial de trauma associado ocasionado pela colocação de clipes sobre o FNVC ${ }^{36}$. A energia do laser potencialmente oferece uma dissecção precisa com excelente eficiência hemostática e mínima lesão secundária ao FNVC, podendo representar uma forma de energia alternativa com mínima morbidade aos tecidos adjacentes durante a prostatectomia radical laparoscópica. Gianduzzo et al utilizou o laser Nd: YAG com potência de $8 \mathrm{~W}$ durante a prostatectomia radical laparoscópica com preservação do FNVC, demonstrando uma dissecção rápida, com sangramento pequeno e lesão nos tecidos adjacentes mínima ${ }^{33}$, destacando que o laser KTP tem exatamente metade do comprimento de onda do laser Nd:YAG, e por isso apresenta penetração e dissipação térmica ainda menores ${ }^{34}$.

No presente estudo, foram avaliados e comparados os parâmetros operatórios, funcionais, termográficos e histológicos da mobilização laparoscópica do FNVC utilizando-se o laser KTP, bisturi ultrasônico, e a técnica sem energia térmica com tesoura e clipes metálicos. A análise funcional foi realizada através da neuroestimulação prévia e posteriormente à mobilização do FNVC, utilizando-se para isso o neuroestimulador Cavermap ${ }^{\circledR}$ como descrito na literatura ${ }^{23,37}$. A dissecção com o bisturi ultrasônico resultou na redução da 
resposta erétil à estimulação quando comparado ao laser KTP e à técnica sem emprego de energia térmica, tanto no período imediatamente após a dissecção quanto após 30 dias. Esse resultado é consistente com os estudos previamente publicados por Ong ${ }^{23}$ e Walsh ${ }^{24}$. Em contraste, o laser KTP não apresentou diferença significativa quando comparado à técnica com tesoura e clipes, ou seja, a eficiência da dissecção com tesoura e ligadura foi equivalente, neste estudo.

Tulikangas et al comparou em modelo experimental os efeitos histológicos do eletrocautério monopolar, bipolar, bisturi ultrasônico e laser $\mathrm{CO}_{2}$, mostrando que o eletrocautério apresentou uma dissipação térmica maior, seguida pelo bisturi ultrasônico e pelo laser, concluindo que a utilização da energia laser pode ser benéfica quando houver a necessidade de dissecção ao redor de estruturas importantes que devem ser preservadas ${ }^{38}$.

A dissecção do FNVC foi exeqüível, e não apresentou grandes problemas técnicos nos três grupos, sem diferença no tempo de dissecção entre os mesmos. A mobilização utilizando-se o laser KTP passou de 42 minutos nos primeiros casos para seis minutos nos casos finais, provavelmente pelo adestramento técnico. O sangramento em ambos os grupos que empregaram energia térmica foi inferior à técnica com tesoura e clipes.

O efeito deletério do calor sobre os nervos é tempo e temperatura dependente ${ }^{39}$. O aquecimento de nervos periféricos com mais de $44{ }^{\circ} \mathrm{C}$ por um período maior do que 30 minutos afeta a condução dos impulsos nervosos. A denaturação protéica inicia-se a temperaturas superiores a $60{ }^{\circ} \mathrm{C}$, e é um 
marcador útil para indicar lesão tecidual ${ }^{40}$. A temperatura na extremidade do bisturi ultrasônico excede $150{ }^{\circ} \mathrm{C}$, apresentando uma dissipação de calor significativamente maior do que o laser KTP, nos indicando ser esta a provável razão das diferenças observadas nos resultados funcionais entre os dois grupos. O tamanho dos instrumentos também pode interferir na dissipação térmica, já que a fibra do laser tem apenas $200 \mu \mathrm{m}$. No entanto, a dissipação média de calor do bisturi ultrasônico observado foi de $6.25 \mathrm{~mm}$, propagando altas temperaturas por $5 \mathrm{~mm}$ além do tamanho da lâmina ativa $(1 \mathrm{~mm})$. O laser KTP apresentou uma dissipação térmica de $0.98 \mathrm{~mm}$, excedendo aproximadamente $800 \mu \mathrm{m}$ além do tamanho da fibra. Aumentando ainda mais o efeito deletério do bisturi ultrasônico, observamos que a extremidade do instrumento levou 40 segundos para atingir temperaturas menores que $60{ }^{\circ} \mathrm{C}$, fazendo com que a dissecção romba utilizando o instrumento após sua ativação possa potencialmente lesar os tecidos mobilizados, tornando seu uso para dissecção logo após a ativação desaconselhável nas proximidades do FNVC.

O efeito do laser nos tecidos é influenciado pela potência utilizada, ângulo de incidência do feixe, distância da fibra até o tecido e duração da exposição à energia. Observamos que o laser KTP causou, em média, necrose de $500 \mu \mathrm{m}$ na fáscia lateral da próstata, chegando até $700 \mu \mathrm{m}$ em alguns cortes isolados. No bisturi ultrasônico, a profundidade média de necrose tecidual desde a superfície de corte foi de $2 \mathrm{~mm}$.

O presente estudo apresenta algumas limitações inerentes à avaliação utilizada. Utilizamos uma potência arbitrária de $6 \mathrm{~W}$ no gerador do laser KTP e, 
portanto, os resultados poderiam ser diferentes se esse ajuste fosse submetido a uma maior variabilidade. As lesões térmicas sub-letais podem ter se dissipado além da área de necrose, podendo ter sido subestimadas na análise histológica. Embora os achados patológicos não mostrem o impacto na função do nervo, devemos interpretar esses resultados em associação com o resultado da análise funcional através da neuroestimulação do FNVC. A avaliação termográfica foi realizada em fragmentos de peritôneo, e não na fáscia prostática propriamente dita. O estudo foi realizado em modelo canino e seus resultados podem não ser totalmente reprodutíveis na prática clínica, devido a diferenças anátomofisiológicas. Além disso, o período de 30 dias pode ter sido insuficiente para a recuperação funcional de uma lesão tecidual não letal. Por outro lado, devemos ressaltar como dado positivo deste estudo a avaliação de três grupos homogêneos, confrontando técnicas cirúrgicas muito utilizadas na prática clínica, evidenciando dados objetivos na agressão sobre o FNVC. Embora no modelo utilizado a dissecção do feixe neuro-vascular cavernoso empregando o laser KTP tenha se mostrado promissora, promovendo uma hemostasia adequada e preservação funcional, outros estudos são necessários para nos certificar de seu verdadeiro impacto clínico na prostatectomia radical laparoscópica com preservação do FNVC, avaliando a agressão tecidual com diferentes escalas de energia térmica do laser e com maior número de casos.

Os resultados apresentados neste estudo podem ter um impacto importante na técnica da prostatectomia radical minimamente invasiva. Com maior experiência na utilização do laser KTP, essa forma de energia pode ser 
empregada de forma única e contínua na realização do procedimento. Tanto a precisão quanto a eficiência do laser podem ser maximizadas com a implantação deste dispositivo na prostatectomia radical robô-assistida, que está crescendo mundialmente em larga escala nos últimos anos, contribuindo para uma hemostasia mais eficaz e menor agressão ao FNVC. Atualmente, o laser KTP já está sendo utilizado na prática clínica como única forma de energia durante a prostatectomia radical laparoscópica e prostatectomia radical robôassistida na Cleveland Clinic, com resultados a serem publicados em futuro próximo. 
Conclusões 
1. O laser KTP apresentou hemostasia superior à técnica sem a utilização de energia térmica e semelhante ao bisturi ultrasônico na dissecção laparoscópica do feixe neuro-vascular cavernoso.

2. O laser KTP produziu lesão mínima aos tecidos adjacentes, com dissipação térmica menor do que o bisturi ultrasônico.

3. A dissecção laparoscópica com o laser KTP apresentou resultados funcionais similares à técnica sem emprego de energia térmica com tesoura e clipes metálicos.

4. A utilização do bisturi ultrasônico prejudicou a função dos nervos cavernosos, sendo prudente evitar o uso desta forma de energia próximo ao feixe neuro-vascular cavernoso durante sua dissecção laparoscópica. 


\section{Anexos}


Anexo 1. Colocação esquemática dos trocartes durante o estudo.

$$
A=10 \mathrm{~mm}, B=5 \mathrm{~mm}, C=2 \mathrm{~mm}
$$

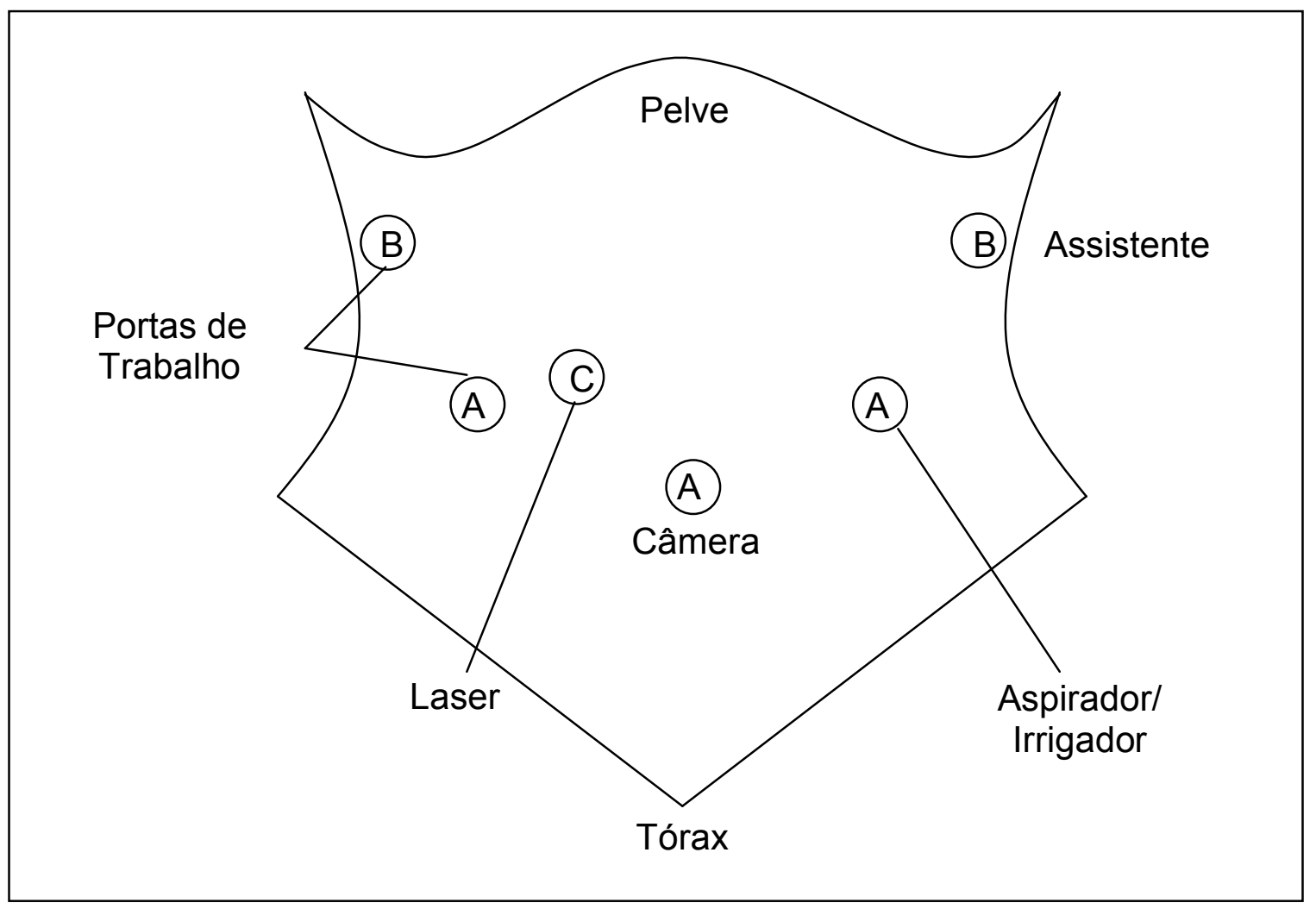


Anexo 2. Mobilização do feixe neuro-vascular cavernoso utilizando-se o laser

KTP

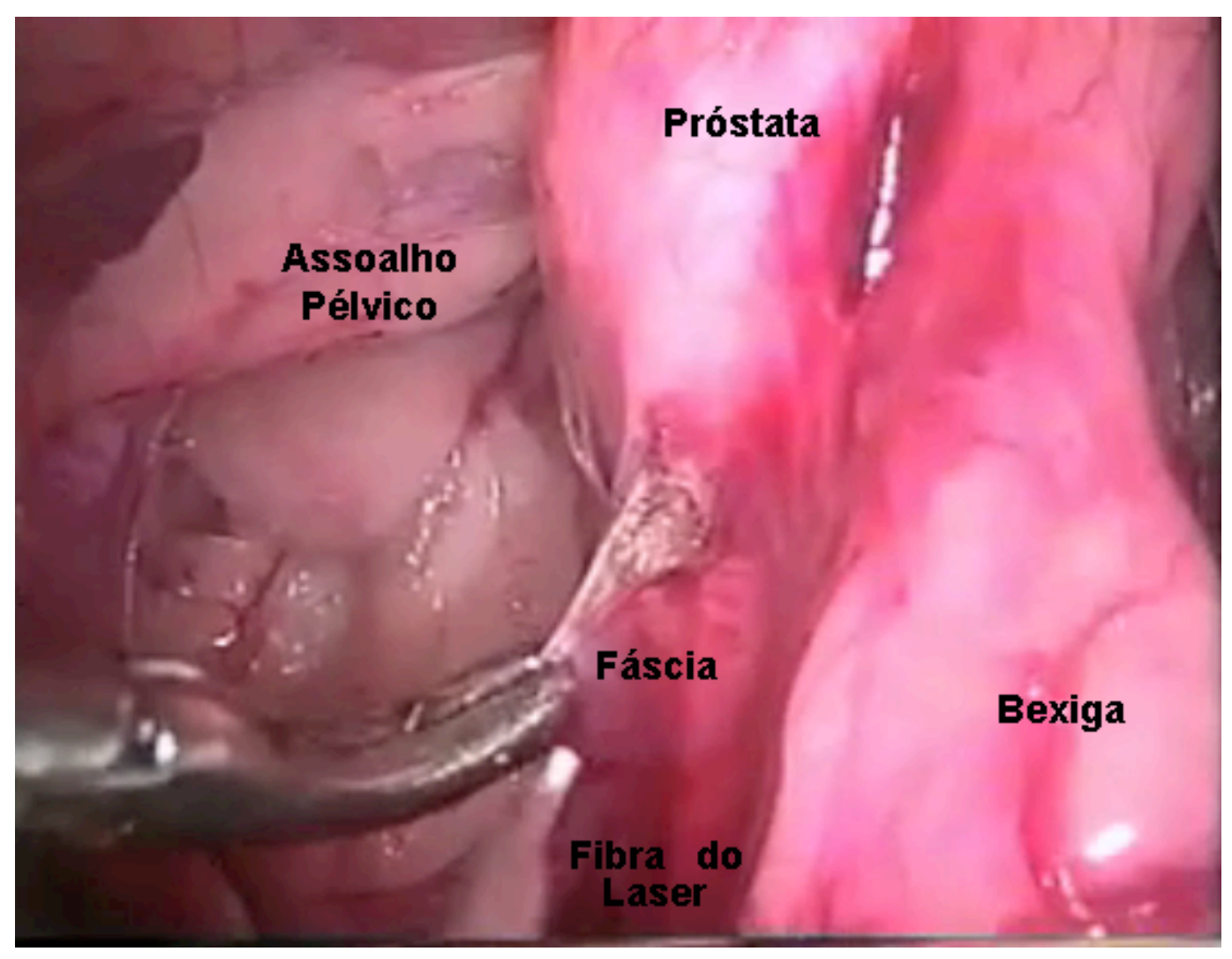


Anexo 3. Mapeamento termográfico de peritôneo parietal incisado com laser KTP com 6 Watts (Temperaturas $>60{ }^{\circ} \mathrm{C}$ mostradas em verde)

Dissipação térmica $>60{ }^{\circ} \mathrm{C}=0.98 \mathrm{~mm}$

\section{Instrumento}

de

Laser

$\mathrm{T}>60 \mathrm{C}$

$0.98 \mathrm{~mm}$

\section{Peritôneo}

Peritôneo

Incisado 
Anexo 4. Mapeamento termográfico de peritôneo parietal peritôneo parietal incisado com bisturi ultrasônico (Temperaturas $>60^{\circ} \mathrm{C}$ mostradas em verde)

Dissipação térmica $>60{ }^{\circ} \mathrm{C}=6.25 \mathrm{~mm}$.

\section{Peritôneo}
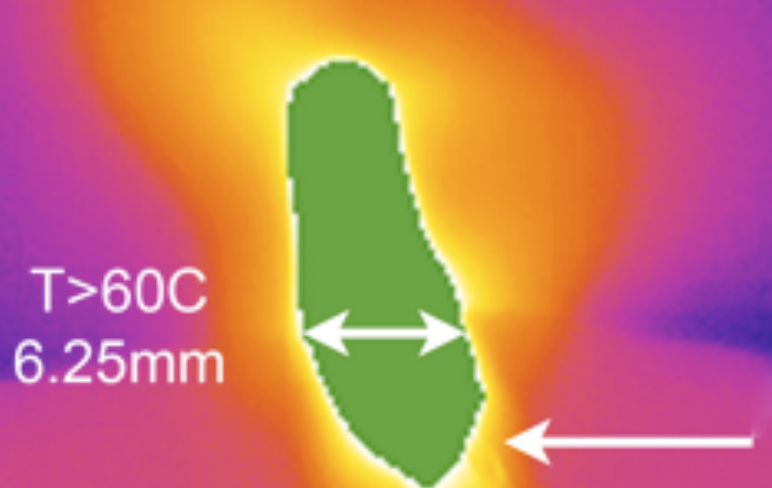

Bisturi 
Anexo 5. Histologia do feixe neuro-vascular cavernoso dissecado com laser KTP (aumento de 20 vezes)

SC - superfície de corte

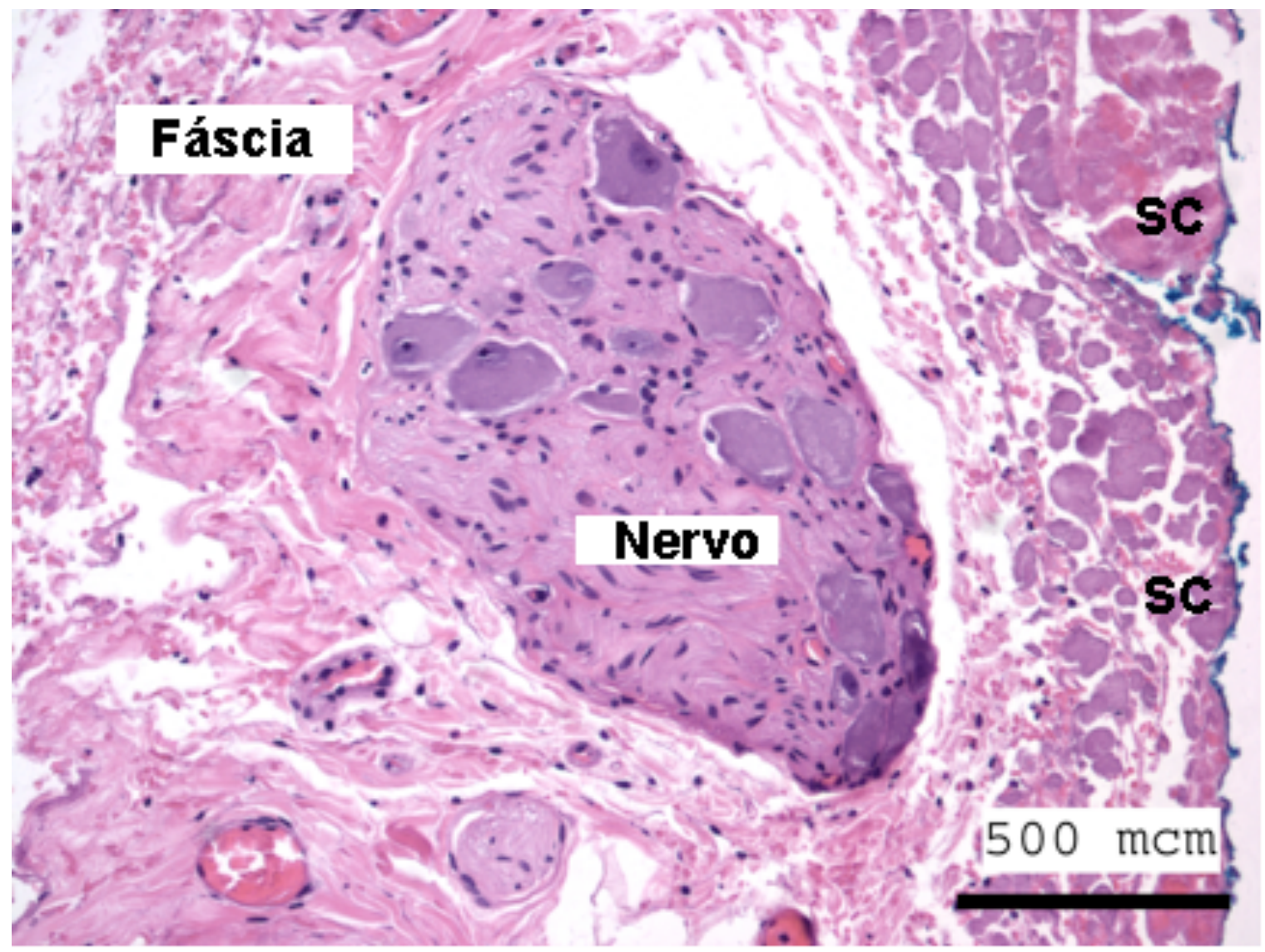




\section{Referências}


1. Brasil. Ministério da Saúde. Instituto Nacional do Câncer. Neoplasias da próstata [internet]. (Acesso 10/02/2007 ]. Diponível em: www.inca.gov.br: Câncer de Próstata, vol. 2006 http://www.inca.gov.br/estimativa/2006/.

2. Reiter RE, deKernion JB. Epidemiology and Prevention of Prostate Cancer. In: Campbell MF, Walsh PC, Retik AB. Campbell's Urology. $8^{a}$ ed. Philadelphia: Saunders; 2002.

3. Bill-Axelson A, Holmberg L, Ruutu M, Häggman M, Andersson SO, Bratell S, Spångberg A, Busch C, Nordling S, Garmo H, Palmgren J, Adami HO, Norlén BJ, Johansson JE; Scandinavian Prostate Cancer Group Study No. 4. Radical prostatectomy versus watchful waiting in early prostate cancer. N Engl J Med. 2005; 352(19): 1977-84.

4. Young $\mathrm{HH}$. The early diagnosis and radical cure of carcinoma of the prostate: being a study of 40 cases and presentations of a radical operation which was carried out in 4 cases. Johns Hopkins Hosp Bull. 1905; 16: 315-21.

5. Memmelaar J. Total prostatovesiculectomy; retropubic approach. J Urol. 1949; 62(3): 340-8. 
6. Reiner WG, Walsh PC. An anatomical approach to the surgical management of the dorsal vein and Santorini's plexus during radical retropubic surgery. J Urol. 1979; 121(2): 198-200.

7. Costello AJ, Brooks M, Cole OJ. Anatomical studies of the neurovascular bundle and cavernosal nerves. BJU Int. 2004; 94(7): 1071-6.

8. Takenaka A, Murakami G, Matsubara A, Han SH, Fujisawa M. Variation in course of cavernous nerve with special reference to details of topographic relationships near prostatic apex: histologic study using male cadavers. Urology. 2005; 65(1): 136-42.

9. Walsh PC. Radical prostatectomy for localized prostate cancer provides durable cancer control with excellent quality of life: a structured debate. J Urol. 2000; 163(6): 1802-7.

10.Walsh PC. Quality of life after radical prostatectomy or watchful waiting. J Urol. 2003; 169(4): 1588-9.

11. Steineck G, Helgesen F, Adolfsson J, Dickman PW, Johansson JE, Norlén BJ, Holmberg L; Scandinavian Prostatic Cancer Group Study Number 4. Quality of life after radical prostatectomy or watchful waiting. N Engl J Med. 2002; 347(11): 790-6. 
12. Penson DF, Litwin MS, Aaronson NK. Health related quality of life in men with prostate cancer. J Urol. 2003; 169(5): 1653-61.

13. Catalona WJ, Carvalhal GF, Mager DE, Smith DS. Potency, continence and complication rates in 1,870 consecutive radical retropubic prostatectomies. J Urol. 1999; 162(2): 433-8.

14. Guillonneau B, Cathelineau X, Barret E, Rozet F, Vallancien G. Laparoscopic radical prostatectomy: technical and early oncological assessment of 40 operations. Eur Urol. 1999; 36(1): 14-20.

15. Abbou CC, Hoznek A, Salomon L, Lobontiu A, Saint F, Cicco A, Antiphon $\mathrm{P}$, Chopin D. Prostatectomie radicale laparoscopique realisee a distance par robot. A propos d'un cas. Prog Urol. 2000; 10(4): 520-3.

16. Pasticier G, Rietbergen JB, Guillonneau B, Fromont G, Menon M, Vallancien G. Robotically assisted laparoscopic radical prostatectomy: feasibility study in men. Eur Urol. 2001; 40(1): 70-4.

17. Erdogru T, Teber D, Frede T, Marrero R, Hammady A, Seemann O, Rassweiler J. Comparison of transperitoneal and extraperitoneal laparoscopic radical prostatectomy using match-pair analysis. Eur Urol. 2004; 46(3): 312-20. 
18. Rassweiler J, Hruza M, Teber D, Su LM. Laparoscopic and robotic assisted radical prostatectomy--critical analysis of the results. Eur Urol. 2006; 49(4): 612-24.

19. Klotz L, Heaton J, Jewett M, Chin J, Fleshner N, Goldenberg L, Gleave M. A randomized phase 3 study of intraoperative cavernous nerve stimulation with penile tumescence monitoring to improve nerve sparing during radical prostatectomy. J Urol. 2000; 164(5): 1573-8.

20. Rehman J, Christ GJ, Kaynan A, Samadi D, Fleischmann J. Intraoperative electrical stimulation of cavernosal nerves with monitoring of intracorporeal pressure in patients undergoing nerve sparing radical prostatectomy. BJU Int. 1999; 84(3): 305-10.

21. Tsujimura A, Miyagawa $\mathrm{Y}$, Takao T, Matsumiya $\mathrm{K}$, Nakayama $M$, Tsujimoto Y, Takaha N, Nishimura K, Nonomura N, Takada T, Fujioka H, Kurokawa K, Aozasa K, Okuyama A. Significance of electrostimulation in detecting neurovascular bundle during radical prostatectomy. Int J Urol. 2006; 13(7): 926-31.

22. Gill IS, Ukimura O, Rubinstein M, Finelli A, Moinzadeh A, Singh D, Kaouk J, Miki T, Desai M. Lateral pedicle control during laparoscopic radical prostatectomy: refined technique. Urology. 2005; 65(1): 23-7. 
23. Ong AM, Su LM, Varkarakis I, Inagaki T, Link RE, Bhayani SB, Patriciu A, Crain B, Walsh PC. Nerve sparing radical prostatectomy: effects of hemostatic energy sources on the recovery of cavernous nerve function in a canine model. J Urol. 2004; 172(4 Pt 1): 1318-22.

24. Walsh PC. Anatomic radical prostatectomy: evolution of the surgical technique. J Urol. 1998; 160(6 Pt 2): 2418-24.

25. Fröhling MA, Schlote W, Wolburg-Buchholz K. Nonselective nerve fibre damage in peripheral nerves after experimental thermocoagulation. Acta Neurochir (Wien). 1998; 140(12): 1297-302.

26. Hnatuk LA, Li KT, Carvalho AJ, Freeman JL, Bilbao JM, McKee NH. The effect of bipolar electrocautery on peripheral nerves. Plast Reconstr Surg. 1998; $101(7): 1867-74$.

27. Owaki T, Nakano S, Arimura K, Aikou T. The ultrasonic coagulating and cutting system injures nerve function. Endoscopy. 2002; 34(7): 575-9.

28. Carlander J, Johansson K, Lindström S, Velin AK, Jiang CH, Nordborg C. Comparison of experimental nerve injury caused by ultrasonically activated scalpel and electrosurgery. Br J Surg. 2005; 92(6): 772-7. 
29. van Hillegersberg R. Fundamentals of laser surgery. Eur J Surg. 1997; 163(1): 3-12.

30. Einstein A. Zur quantentheorie der Strahlung. Physikal Z. 1917; 18: 1218.

31. Maiman TH. Stimulated optical radiation in ruby. [carta]. Nature. 1960; 187: 493-4.

32. Goldman L, Ingelman JM, Richfield DF. Impact of the laser on nevi and melanomas. Arch Dermatol. 1964; 90: 71-4.

33. Gianduzzo TR, Chang CM, El-Shazly M, Mustajab A, Moon DA, Eden CG. Laser nerve-sparing laparoscopic radical prostatectomy: a feasibility study. BJU Int. 2007; 99(4): 875-9.

34. Bhatta N, Isaacson K, Bhatta KM, Anderson RR, Schiff I. Comparative study of different laser systems. Fertil Steril. 1994; 61(4): 581-91.

35.Zenk J, Geisthoff UW, Hamadi I, Iro H. In vitro tissue effects of a combined Ho:YAG/Nd:YAG laser: sprinkling of tissue fragments by Ho:YAG laser light may be problematic for oncological interventions. Lasers Surg Med. 1999; 25(5): 396-400. 
36. Chien GW, Mikhail AA, Orvieto MA, Zagaja GP, Sokoloff MH, Brendler CB, Shalhav AL. Modified clipless antegrade nerve preservation in robotic-assisted laparoscopic radical prostatectomy with validated sexual function evaluation. Urology. 2005; 66(2): 419-23.

37. Terada N, Arai Y, Kurokawa K, Ohara H, Ichioka K, Matui Y, Yoshimura K, Yamanaka H, Terai A. Intraoperative electrical stimulation of cavernous nerves with monitoring of intracorporeal pressure to confirm nerve sparing during radical prostatectomy: early clinical results. Int J Urol. 2003; 10(5): 251-6.

38. Tulikangas PK, Smith T, Falcone T, Boparai N, Walters MD. Gross and histologic characteristics of laparoscopic injuries with four different energy sources. Fertil Steril. 2001; 75(4): 806-10.

39. Haveman J, Van Der Zee J, Wondergem J, Hoogeveen JF, Hulshof MC. Effects of hyperthermia on the peripheral nervous system: a review. Int J Hyperthermia. 2004; 20(4): 371-91.

40. Kinoshita T, Kanehira E, Omura K, Kawakami K, Watanabe Y. Experimental study on heat production by a $23.5-\mathrm{kHz}$ ultrasonically activated device for endoscopic surgery. Surg Endosc. 1999; 13(6): 6215. 